\title{
MARKER ASSISTED SCREENING OF NEPALESE WHEAT GENOTYPES AND ADVANCED LINES FOR RESISTANCE TO DIFFERENT RACES OF WHEAT RUST SPECIES
}

\author{
S. Sharma ${ }^{1}$, S. K. Ghimire ${ }^{1}$, R. K. Niroula ${ }^{2}$, B. R. Ojha ${ }^{1}$ and D. B. Thapa ${ }^{2}$ \\ ${ }^{1}$ Institute of Agriculture and Animal Sciences, Tribhuvan University, Nepal \\ ${ }^{2}$ Nepal Agricultural Research Council, Kathmandu, Nepal
}

\begin{abstract}
Primers tightly linked to genes of interest are valuable tools in rust resistant wheat breeding. A research was conducted with the objective to detect the source of rust resistant genes and further utilize as an important weapon in gene pyramiding. A total of forty gene-specific primer sets consisting of $\mathrm{Lr}$, $\mathrm{Yr}$ and $\mathrm{Sr}$ associated gene specific markers were applied for screening thirty wheat genotypes. Based on the value of band size, the presence of concerned resistance gene was predicted and binary scoring was done for further analysis. Softwares Genealex and NTSYSpc2.1 were applied for detail analysis. Some genes like Lr29, Lr51, YrCH42, Sr36, etc. were detected in many of the tested genotypes but some genes like Lr47, Sr39, Sr24 were absent in tested lines. Among tested genotypes, Chyakhura-1 possesses highest number of rust resistant genes and Annapurna-4 bears lowest number of genes. Highest value of Jaccard coefficient was obtained between genotypes Danphe-1 and Danphe-2 (0.87) showing their greatest resemblance. UPGMA dendrogram grouped thirty genotypes into distinct four clusters. Percentage of Polymorphic loci was 88.57 and grand mean of observed heterozygosity (Ho) was found to be 0.193 (S.E 0.057).
\end{abstract}

Key words: Genotypes, Primers, Marker assisted screening, Polymorphism.

\section{INTRODUCTION}

Wheat is the third important cereal grain crop of Nepal after rice and maize. In Nepal, wheat crop occupies approximately 0.767 million hectares and produces 1.746 million metric tons of grains. National productivity of this crop is $2275 \mathrm{~kg} / \mathrm{ha}$ (MoAC, 2012). There are numerous wheat diseases, caused by various pathogens. Among these, rust diseases have, for years, been a major concern and problem for breeders, farmers and commercial seed companies (Wiese, 1977; Marsalis and Goldberg, 2006). They are notable, historically, for their severe attacks on wheat crop.

Many rust resistance genes have been identified but a limited number of those genes are still effective to the pathogen population in our region. The released varieties are likely to be breakdown in terms of its resistance to biotic/abiotic stresses and also thereby need new cultivars having higher yield as well as better quality performance. The wheat rust fungi cause the potentially most devastating diseases of wheat and genetic control is a highly effective and cost-saving alternative to chemicals. The existing varieties are likely to breakdown in terms of its resistance to rust disease and also need further improvement in yield potential.

Nepalese wheat varieties are assumed to be the precious sources of resistant gene. But, the appropriate molecular genotyping of these cultivars is lacking. Hence, research on marker assisted rust resistant gene screening of wheat lines is new frontier in improving environment; increasing 
production and productivity at low cost in the country. Developing, identifying, multiplying and disseminating high yielding varieties along with resistance to leaf, yellow and stem rusts is urgent need of country to safeguard the country from food shortages problem. Minimizing the loss caused by diseases is one of the solutions to increase the productivity. Any primers tightly linked to genes of interest are probably the most attractive markers since no further manipulations are needed for implementation. In this light; the current research is focused on marker assisted screening of wheat lines, using rust resistant gene specific markers.

\section{Selection of wheat genotypes}

\section{MATERIALS AND METHODS}

Thirty wheat genotypes were used for marker assisted screening using different races of rust resistant primers. The genotypes include Nepalese released and pre-released improved varieties of NARC, local cultivars, and other advanced breeding lines. This selection encompasses the broad range of genotypes so that more sources of various races of Lr, Yr and $\mathrm{Sr}$ genes can be identified. Nepalese genotypes used were mostly of mid-hill areas and accessions were collected from Agriculture-Botany Division, NARC; Khumaltar

\section{Research laboratory}

Detail molecular study was done in Molecular Laboratory, Biotechnology Division, National Agriculture Research Center (NARC), Khumaltar Nepal in 2012.

\section{Genomic DNA extraction}

Seeds of studied genotypes were kept for germination on Petridis, and 4-5 days seedlings were used as source of DNA. Leaves and roots were collected from seedlings was subjected to liquid nitrogen for DNA extraction using "Modified CTAB method "

\section{DNA quantification and dilution}

Dilution of DNA by adding $10 \mu \mathrm{l}$ of DNA solution to $90 \mu \mathrm{l}$ of distilled water in a micro-tube, were prepared and mixed well. Spectrophotometer was used for the quantification purpose. Based on the obtained values from DNA Quantification, concentration of DNA was calculated for working sample.

\section{Gene specific primers used for MAS}

Wheat genotypes were mapped by using 40 gene-specific primer sets.

\section{PCR Amplification}

PCR process was accomplished by Thermocycler PCR machine (PTC-100, MJ Research, Inc., Watertown, Massachusetts, USA) with adjustment of appropriate amplification program for 35 cycles.

\section{Gel electrophoresis and autoradiography}

Amplification products was visualized with different sets of primers on $1.5 \%$ agarose gel with 1x TBE buffer and detected by staining with an ethidium bromide. 


\section{Statistical analysis}

Based on the value of band size, the presence of associated trait in the genotypes was predicted. Different softwares such as, MS-EXCEL, NTSYS-PC, GeneAlex 6 (Peakall and Smouse 2006) were used for the data analysis in a binary matrix form. The amplified products were scored as bands on visualization on gel on UV illuminator. Only the reliable bands were included in analysis. These scored bands were computed into binary matrix. The presence of the corresponding resistant band was scored as "1" and absent bands was scored as " 0 ". Genetic diversity measures such as the number of alleles per locus, size range, Shannon's Information Index, observed heterozygosity, expected heterozygosity, unbiased expected heterozygosity, fixation index and gene frequencies were estimated. The genetic similarities were calculated for each pair of inbred using the Jacard Similarity Coefficient matrix. The similarity matrix was used to construct UPGMA (un-weighted pair group methods using arithmetic averages algorithm) clustering using NTSYS-pc.V.2.11.

\section{RESULTS AND DISCUSSION}

Biotic stress resistance emerges as principal selection criteria in contemporary wheat selection objectives. Rust disease continues to cause huge losses worldwide in wheat production due to reliance on cultivars with race-specific resistance and the high level of virulence variation in rust pathogens. A new approach called "genomic selection" that is based on the widespread conventional selection with the use of information from the molecular markers will facilitate breeding program through better combination of cost, time, precision and durability. Marker assisted screening (MAS) is successful and innovative breeding tool in this context.

There is varying intensity of rust resistance gene present among the tested thirty genotypes. Genotypes also revealed diversity in terms of their relatedness with respect to different rust resistant genes. Out of forty gene specific markers used in study, five markers namely XABC465, RK2 (SCAR Lr 24), ARBI1RGA-2, Sr24\#12 and Sr39\#22r linked respectively with Lr47, Lr24, Lr24, Sr24 and Sr39 don't show any distinct bands. So, rest 35 markers were only used in Genetic diversity and analysis.

\section{Banding patterns and screening of resistant genotypes}

Out of thirty five markers that show distinct bands; four markers XGWM533, CsSr2, BE50070 and WMC 633 don't show any bands of resistant size but Primer XAGA7-1B showed resistant band in all of the tested genotypes. 
Table 1. Marker assisted evaluation (Markerwise)

\begin{tabular}{|c|c|c|c|c|}
\hline S.N. & Features/ Primers & Respective gene & $\begin{array}{l}\text { Band size } \\
\text { bp }\end{array}$ & $\begin{array}{l}\text { No. of Genotypes with gene } \\
\text { presence }\end{array}$ \\
\hline 1 & XGWM319 & Sr 36 & 170 & 27 \\
\hline 2 & Lr29F18 & Lr29 & 900 & 27 \\
\hline 3 & XGDM87 & Lr 50 & 110 & 7 \\
\hline 4 & XWMC44-1B & Lr46, Yr29 & 242 & 10 \\
\hline 5 & XGWM382 & Lr50 & 139 & 5 \\
\hline 6 & XGWM413 & Yr15 & 95 & 9 \\
\hline 7 & XGWM391 & Sr 35 & 180 & 23 \\
\hline 8 & XCFA2076 & Sr 35 & 210 & 23 \\
\hline 9 & XGWM498 & YrCH42; Yr24; Yr26 & $159-161$ & 29 \\
\hline 10 & XGWM533 & $\mathrm{Sr} 2$ & 120 & None \\
\hline 11 & XABC465 & Lr47 & 282 & No Bands \\
\hline 12 & XGWM259-1B & Lr46; Yr29 & 105 & 8 \\
\hline 13 & WMS639 & Sr exp 2 & 200 & 10 \\
\hline 14 & XAGA7-1B & $\operatorname{Lr} 51$ & 783 & 30 \\
\hline 15 & XBARC352-7D & Lr34 & 248 & 13 \\
\hline 16 & XGWM264 & Yr 15 & 222 & 6 \\
\hline 17 & XGWM273 & Yr 26 & 190 & 10 \\
\hline 18 & XWMC656 & Yr 45 & 280 & 4 \\
\hline 19 & XBARC187-1B & Yr26, Yr CH42 & 220 & 20 \\
\hline 20 & XWMC631 & Sr exp 1 & 220 & 26 \\
\hline 21 & XBARC6 & Yr45 & 360 & 4 \\
\hline 22. & STS Lr 19 (RK1) & $\operatorname{Lr} 19$ & 130 & 7 \\
\hline 23 & CFD49 & $\mathrm{Sr} \mathrm{Cad}$ & 275 & 18 \\
\hline 24 & XGWM192 & Yr 46 & $230 / 130$ & 29 \\
\hline 25 & XBARC80-1B & Lr46 & 95 & 9 \\
\hline 26 & XGWM130-7D & Lr34 & 132 & 20 \\
\hline 27 & XGWM18 & Yr CH52 & 184 & 14 \\
\hline 28 & WMC313 & Lr28 & 320 & None \\
\hline 29 & XGWM498-1Band & Yr CH42 & 160 & 11 \\
\hline 30 & PK54 & $\begin{array}{l}\text { Yr (hom to gama } \\
\text { gladillin) }\end{array}$ & 190 & 16 \\
\hline 31 & GWM508 & Lr53 & 135 & 15 \\
\hline 32 & RK2 (SCAR Lr 24) & $\operatorname{Lr} 24$ & 700 & No bands \\
\hline 33 & CFD1 & $\operatorname{Lr} 53$ & 225 & 10 \\
\hline 34 & ARBI1RGA-2 & Lr24 & 161 & No bands \\
\hline 35 & Sr24\# 12 & $\operatorname{Sr} 24$ & 500 & No bands \\
\hline 36 & $\operatorname{Sr} 39 \# 22 r$ & Sr 39 & 487 & No bands \\
\hline 37 & E1(Exon 1) & Yr 10 & 754 & 18 \\
\hline 38 & WMC 633 & Sr 22 & 117 & None \\
\hline 39 & BE500705 & Sr 39 & 166 & None \\
\hline 40 & $\mathrm{CsSr} 2$ & $\operatorname{Sr} 2$ & 172 & None \\
\hline
\end{tabular}


Among tested genotypes, Chyakhura\#1 have possess highest number of rust resistant genes (24) and Annapurna-4, bears lowest number of genes (12).

Table 2. Marker assisted evaluation (Genotypewise)

\begin{tabular}{|c|c|c|}
\hline S.N. & Grown Parents & No. of Genes present based on MAS \\
\hline 1 & WK 1182 & 13 \\
\hline 2 & WK 1204 & 18 \\
\hline 3 & WK 1481 & 16 \\
\hline 4 & WK 1627 & 21 \\
\hline 5 & WK 1661 & 20 \\
\hline 6 & WK 1803 & 17 \\
\hline 7 & WK 1804 & 13 \\
\hline 8 & WK 1905 & 20 \\
\hline 9 & WK 1906 & 16 \\
\hline 10 & WK 1907 & 18 \\
\hline 11 & WK 1909 & 19 \\
\hline 12 & WK 1912 & 22 \\
\hline 13 & Chyakhura \# 1 ( 3 EBWYT 515) & 24 \\
\hline 14 & Chewink \# 1 ( 3 EBWYT 514) & 22 \\
\hline 15 & Munal \# 1 & 21 \\
\hline 16 & Danphe \# 1 & 18 \\
\hline 17 & Danphe \# 2 & 15 \\
\hline 18 & Annapurna - 4 & 12 \\
\hline 19 & Godwari Local & 13 \\
\hline 20 & Hanse Seto & 16 \\
\hline 21 & 30 ESWYT 125 & 18 \\
\hline 22 & SW 2148 & 19 \\
\hline 23 & NOURIN 61 / MILAN// LONG MAI 19 & 17 \\
\hline 24 & KENYA NYANGUMI & 16 \\
\hline 25 & BGUA/4/GOV/AZ//MUS/3/KEA & 14 \\
\hline 26 & KENYA SWARA & 15 \\
\hline 27 & CROC_1/ AE.SQUARROSA (205)// KAUZ/ 3/ SASIA & 19 \\
\hline 28 & Bezostay 1 & 15 \\
\hline 29 & WK 1444 & 15 \\
\hline 30 & WK 1710 & 15 \\
\hline
\end{tabular}

\section{Genetic diversity measures}

Among the set of gene specific markers used in study, $88.57 \%$ turned out to be polymorphic. Out of 35 markers that showed distinct bands; four markers namely XAGA7-1B, XGWM498, 
XBARC187-1B and E1 (Exon 1) were found to be monomorphic.. Among Polymorphic markers, maximum number of different alleles (Na) was obtained in XGWM264 (6) followed by WMS639, XBARC80-1B and CsSr2F (5). Mean value of Na was found 3 (S.E. 0). Number of effective alleles (Ne) was maximum in Cssr2F primer (4.444) followed by XGWM 264 (4.073) and minimum in XGWM319 (1.220) among the polymorphic markers. Mean Value of Ne was obtained 2.377 (S.E. 0.164). Shannon's information index (I) was found maximum in XGWM264 (1.598) followed by CsSr2F (1.544). In contrast, I value was found minimum in XGWM 319 (0.325) and BE500705F (0.451) respectively. Mean Shannon's information index was observed to be 0.869 (S.E. 0.076). Observed heterozygosity (Ho) was found highest in XBARC6 and XGWM192 (1) among the polymorphic primers. Mean Ho value was observed to be 0.193 with S.E. 0.057. Expected heterozygosity (He) was found highest in CsSr2F (0.775) followed by XGWM264 (0.754) and mean expected heterozygosity was found 0.496 (S.E.0.039). Unbiased expected heterozygosity (UHe) was found maximum in CsSr2F (0.795) followed by XGWM264 (0.768) andWMS639 (0.762). Mean UHe value was observed to be 0.505 (S.E. 0.040). Fixation index value (F) was found maximum in 18 of the polymorphic markers (1). In contrast, minimum fixation index was found in primer XGWM192 (-1) and XGWM391 (-0.699). Mean value of F was observed to be 0.617 (S.E.0.104).

\section{Jaccard coefficient similarity matrix}

From the Jaccard coefficient similarity matrix (fig 1), highest value of Jaccard coefficient was obtained between genotypes Danphe-1 and Danphe -2 (0.87) showing their greatest resemblance with respect to presence of rust resistant genes. The value was followed by that between KENYA NYANGUMI and KENYA SWARA (0.78). Lowest coefficient was observed between genotypes WK 1906 and Godawari local as well as between Chewink\# 1 and Annapurna- 4 (0.20) showing the least resemblance in terms of presence of rust resistant genes. The least value was followed in between the genotypes Godawari local and Danphe -1 (0.21).

\section{UPGMA dendrogram and principal coordinates analysis}

Based on Jaccard coefficient similarity matrix, UPGMA dendrogram was constructed. UPGMA dendrogram grouped thirty genotypes into distinct four clusters (Figure 1). This result was similar and same clusters are also obtained from Principal coordinate analysis (1 vs 2) (Figure 2). Distribution of different genotypes in different cluster is shown in Table 3.

Table 3. Grouping of genotypes into clusters as revealed by UPGMA dendrogram and PCA analysis

\begin{tabular}{ll}
\hline Number & Genotypes \\
\hline $\begin{array}{l}\text { Cluster I } \\
\text { (7 genotypes) }\end{array}$ & WK 1182; WK 1481; WK 1803; WK 1804; WK 1204; WK 1627 and WK 1661. \\
$\begin{array}{l}\text { Cluster II } \\
\text { (8 genotypes) }\end{array}$ & $\begin{array}{l}\text { NOURIN 61 / MILAN// LONG MAI 19; KENYA NYANGUMI; KENYA SWARA; } \\
\text { SASIA; Bezostay 1; WK 1444 and WK 1710 }\end{array}$ \\
$\begin{array}{l}\text { Cluster III } \\
\begin{array}{l}\text { (10 genotypes) } \\
\text { Cluster IV } \\
(5 \text { genotypes) }\end{array}\end{array}$ & Danphe \# 1; Danphe \# 2 and WK 1912 \\
\hline
\end{tabular}


요

สิ

$\stackrel{\infty}{\sim}$

$\hat{\lambda}$

ส

2

$\stackrel{4}{ }$

ก

ส

$\vec{\wedge}$

กิ

9

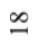

$=$

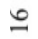

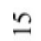

$\pm$

9

$\simeq$

$=$

음

$a$

$\infty$

$r$

6

n

$\checkmark$

m

N

\section{$-8$}

-

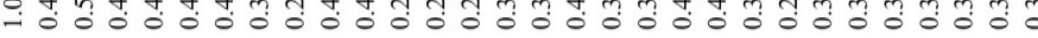

-

\&

ㅇำ

\& กี่

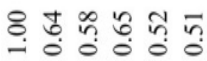

\&

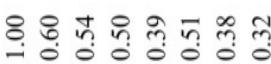

\&

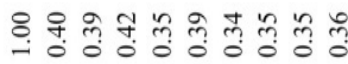

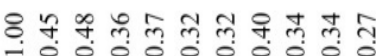

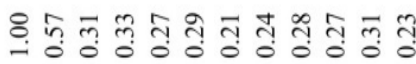

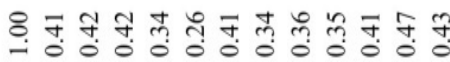

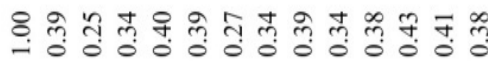

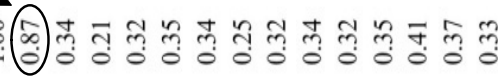

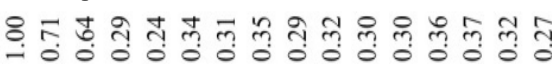

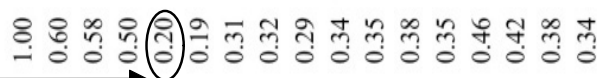

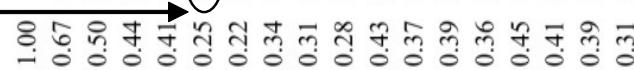

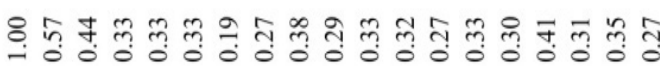

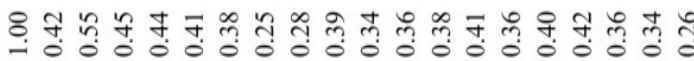

ช

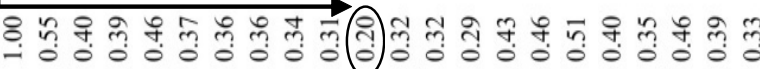

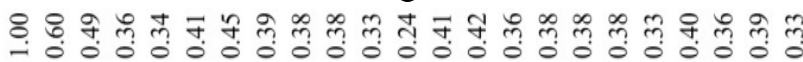

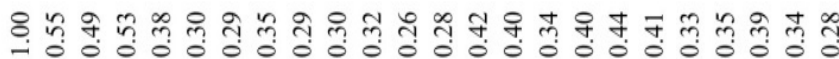

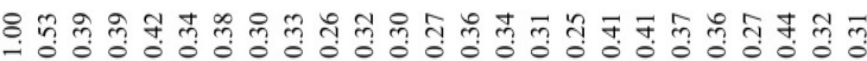

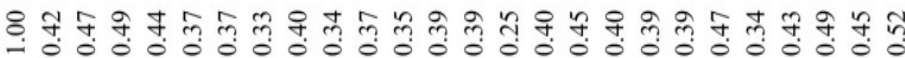

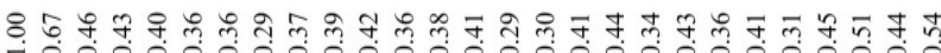

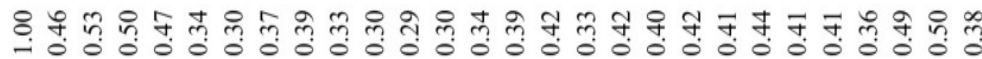

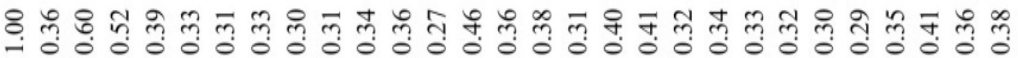

政

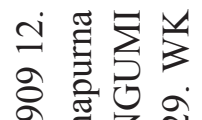

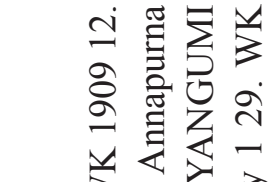
文焉 二 요욛ㄴ $\checkmark$ 芯 승 든 迟\#亦的 光言令 a.

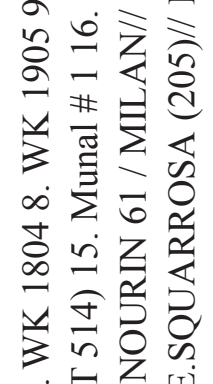
드

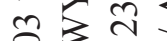

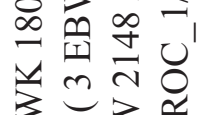
3 is 光 * ธี้ สำ 늘 의 的包分公 तิษ

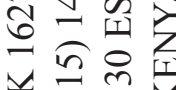
的? उ. $\forall \sum 00$

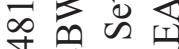
四 $\forall m \cong$ $3=\pi \frac{\pi}{2}$ ri 广 잃

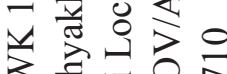

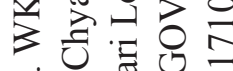

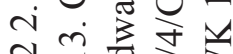
๙ 光永

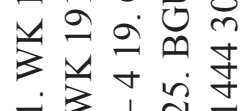




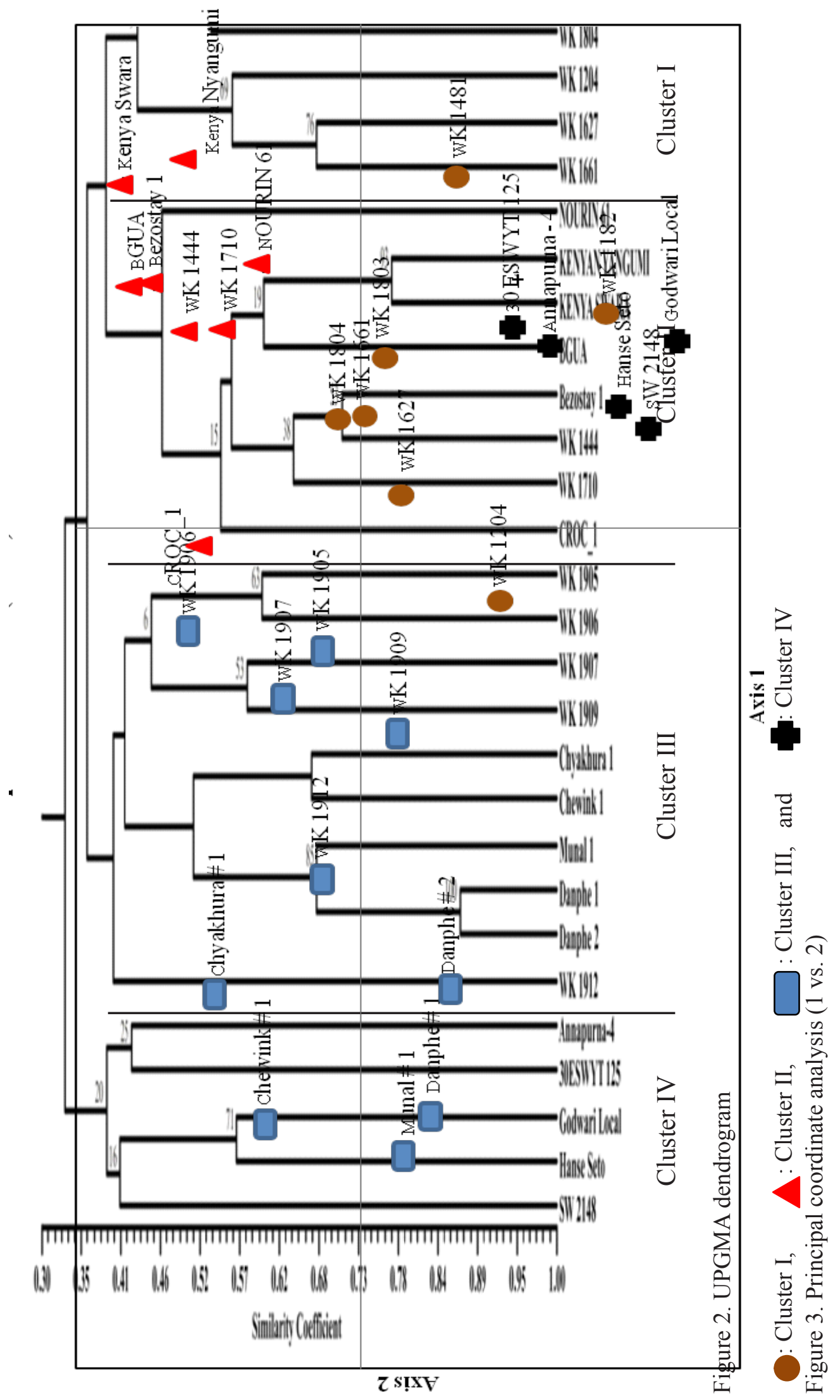




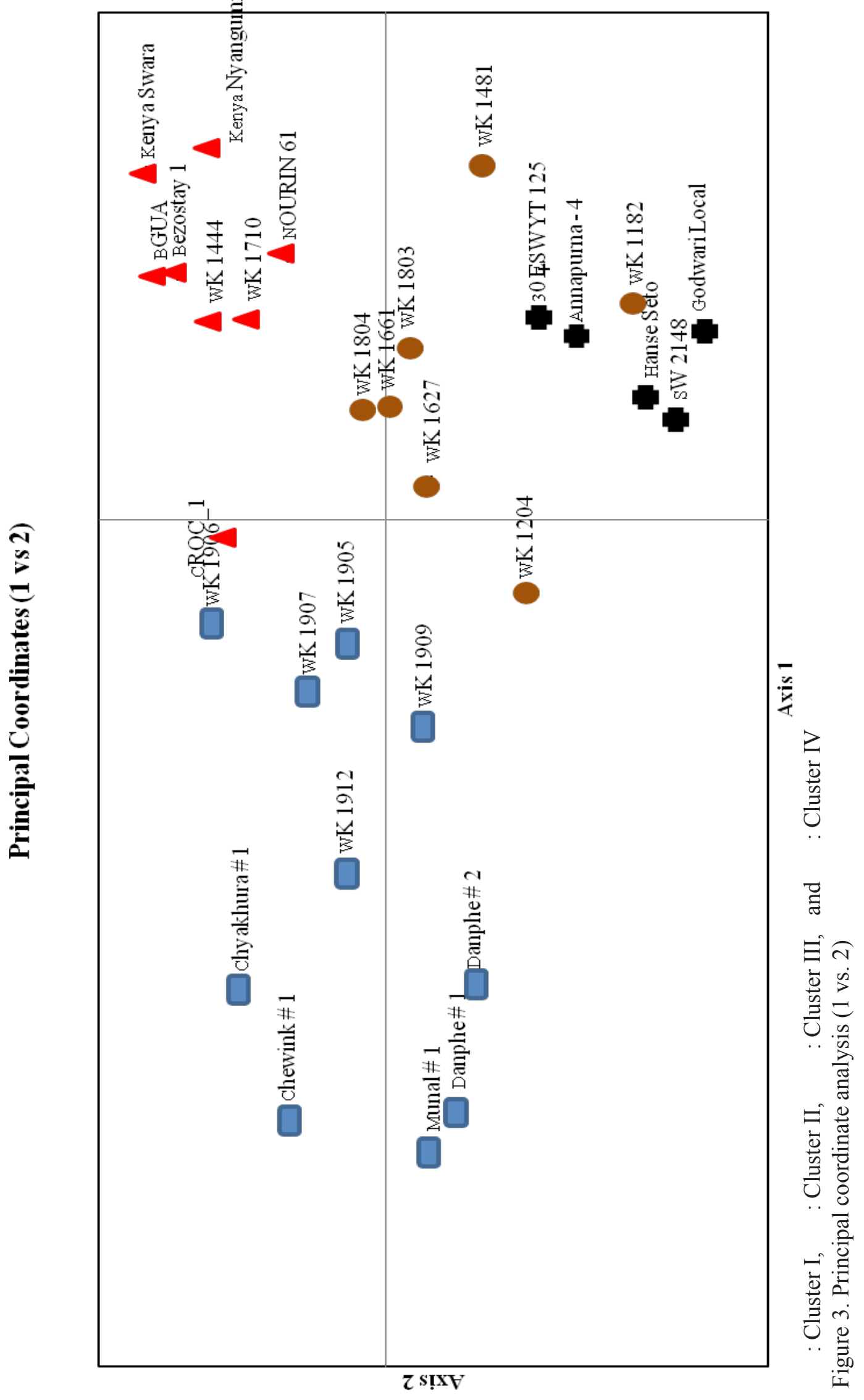




\section{Tests for Hardy- Weinberg equilibrium}

Chi-square test was conducted in case of each polymorphic marker to test for Hardy-weinberg equilibrium. Out of 31 polymorphic markers; all except for XCFA2076 were found highly significant. This indicates that the bands present in most of the polymorphic markers are significantly different among each other. Highest chi-square value was obtained in XBARC 80-1 B (120 at df 10) followed by WMS639 (116 at df 10). In contrast, minimum chi-square value was found in primer XCFA2076 (1.767 at df 3$)$.

\section{CONCLUSION}

There is varying intensity of rust resistance gene present among the tested thirty genotypes. Five gene specific markers didn't show any distinct bands and out of thirty five markers that show distinct bands; four markers XGWM533, CsSr2, BE50070 and WMC 633 don't show any bands of resistant size. In contrast, Primer XAGA7-1B showed resistant band in all of the tested genotypes. Genotype Chyakhura\#1 possess highest number of rust resistant genes and Annapurna-4, bears lowest number of genes. Among the set of gene specific markers used in study, $88.57 \%$ primers revealed polymorphism. Thus, from this study, the presence of rust resistant genes in some Nepalese wheat genotypes and advanced lines were detected with the help of gene specific molecular markers. Genetic relationship among the genotypes with respective to presence of rust resistance gene was also assessed. The current study is worthy as an important tool in gene pyramiding of rust resistant genes in wheat. The results would be equally beneficial as vital means of genetic improvement for wheat rust resistance.

\section{ACKNOWLEDGEMENTS}

Sincere acknowledgement is extended to the Biotechnology Unit, NARC, Khumaltar for providing access to their laboratory and for creating the healthy office environment for conducting the experiment successfully.

\section{REFERENCES CITED}

Adhikari, S. 2009. Epidemioloy and yellow rust resistance of wheat genotypes in mid hills of Nepal. M. Sc. Thesis (unpublished). Department of Plant Pathology. Institute of Agriculture and Animal Science, Rampur.

Agrios, G. N. 2005. Plant Pathlogy. (5 $5^{\text {th }}$ ed.). Elsevier Academic Press.

Chawla, H. S. 2004. Introduction to Plant Biotechnology. (2 ${ }^{\text {nd }}$ ed.). Oxford and IBH publishing Co. Pvt. Ltd, New Delhi.

Chen, X. M. 2005. Epidemiology and control of stripe rust (Puccinia striiformis f. sp. Tritici) on wheat. Can. J. Plant Pathology. 27: 314-337.

FAO. 2011. FAOSTAT. Retrieved February 20, 2013, http://faostat.fao.org/site.

Gene Symbol. Retrived http://www.shigen.nig.ac.jp/wheat/komugi/genes/macgene /2010.html as on 15th Oct. 2012.

Marker Assisted Selection in Wheat Homepage. Retrived from http://maswheat.ucdavis. edu/ Education /index.htm as on $15^{\text {th }}$ Oct. 2012.

Marker Assisted Selection in Wheat. Retrived from http://wheat.pw.usda.gov as on 30 $0^{\text {th }}$ Oct. 2012.

Marsalis, M. A. and N.P. Goldberg. 2006. Leaf, stem and stripe rust diseases of wheat. New Mexico State University Guide A-415. Available at (http://www.cahe. nmsu.edu). Cited December 2012. 
McIntosh, R.A., K. Devos, J. Dubcovsky and W.J. Rogers 2000. Catalogue of gene symbols for wheat. Supplement Wheat Information Service. 91:33-70.

MoAC. 2012. Statistical information on Nepalese agriculture. Government of Nepal, Ministry of Agriculture and Cooperatives. Agribusiness Promotion and Statistics Division, Singh Durbar, Kathmandu, Nepal.

Nei, M. 1973. Analysis of gene diversity in subdivided populations. Proc. Natl. Acad. Sci. U. S. A. 70, 3321-3323.

Rohlf, M. 1998. NTSYS-pc, numerical taxonomy and multivariate analysis system. Version 2.1. Dept. of Ecology and Evolution. State Univ. of New York, U.S.A.

Singh, R.P. and J. Huerta. 1997. Effect of leaf rust resistance gene Lr34 on grain yield and agronomic traits of spring wheat. Crop Sci., 37: 390-395.

Somers, D.J. 2004. A high-density wheat microsatellite consensus map for bread wheat (Triticum aestivum L.). Theoretical and Applied Genetics 109:1105-1114

Tanksley, S.D. 1983. Molecular markers in plant breeding. Plant Molecular Biology Reporter 1: 3-8.

Wellings, C. 2010. Global status of stripe rust. BGRI 2010 Technical Workshop, 30-31 May 2010, St Petersburg, Russia Wellings.

Wiese, M.V. 1977. Compendium of wheat diseases. St. Paul: The American Phytopathological Society. 112 p.

Wiley, E. O. 1981. Phylogenetics: The theory and practice of phylogenetics and systematics. John Wiley, New York.

Ye, G. and K. F. Smith. 2009. Marker-assisted gene pyramiding forcultivar development. Plant. Breed. Rev. 33:219-256. 